'Blogging and Globalization: the Blurring of the Public/Private Spheres.' Aslib Proceedings: New Information Perspectives 2009 61(2):127-138.

Blogging and globalization: the blurring of the public/private spheres

\title{
Gillian Youngs
}

Department of Media and Communication

University of Leicester, Leicester, UK

Abstract

Purpose - The blurring of public and private spheres is among the changes associated with the phenomenon of blogging. In linking this to theories of globalization we can see more clearly how new media transformations have macro as well as micro significance.

Design/methodology/approach - An assessment of blogging is undertaken in the context of theories of globalization, with specific focus on issues related to public/private linkages, the aim being to make theory-practice connections to enhance understanding of the wider implications of blogging.

Findings - The analysis identifies how theories of globalization offer foundational understanding for investigating blogging as a social rather than purely new media development. This relates to the spatial reconfigurations of social, political, economic and cultural life, which have been characteristic of processes of globalization. The ways in which blogging demonstrates the blurring of public and private spheres is usefully understood within this broader spatial framework.

Research limitations/implications - This is a primarily conceptual and theoretical approach with substantive reference to blogging, which remains at the general level rather than looking in detail at different kinds of blogs and their implications. Its contribution is therefore located primarily in the conceptual and theoretical domains. Practical implications - This form of analysis foregrounds public/private sphere boundaries in relation to blogging and could contribute to critical thinking about the social implications of blogging for bloggers and readers alike.

Originality/value - Conceptual and theoretical linkages between theories of globalization, especially in relation to spatial issues, blogging and the burring of public and private. 
Keywords Globalization, Blogging, New media, Internet, Public sphere, Private sphere

Blogging and globalization: the blurring of the public/private spheres

\section{Gillian Youngs}

Department of Media and Communication

University of Leicester, Leicester, UK

\section{Introduction}

This article discusses some of the conceptual and theoretical implications for the blurring of public and private spheres demonstrated by the Web 2.0 phenomenon of blogging in the context of theories of globalization. Its approach is to consider blogging in the broader frame of new media developments rather than as an isolated development, thus focus is placed on how blogging helps us to understand the social manifestations and consequences of new media more generally, as well as introducing specifically new factors that need to be addressed. In this way, blogging is viewed as one of many interconnected threads of online communication that have developed over the history of the Internet. Also, there is an applied approach to thinking conceptually and theoretically about new media. In other words, a sense that many insights about these two areas, draw heavily on innovative new media practices and the ways in which they become established. So, to a certain degree, practice is being read back into concepts and theory, as much as they are being read into practice.

The article is divided into two sections. These are intended to offer different insights into our thinking about private and public spheres in relation to new media. First, the question, what is new about blogging in relation to blurring of public and private spheres will be considered, in order to draw out some of the continuities as well as discontinuities across media developments. The stance here is that thinking critically about where we have come from, even in terms of the relatively short history of the Internet, will not only help our clarity about where we are now, but also thinking about the range of possibilities for the future. Second, the complex mapping of the blurring of public and private spheres in relation to traditionally conceived boundaries of political spheres is considered. What is centrally at stake here is the 
diverse meanings of the social spaces of new media blogging in the setting of traditionally configured geopolitical communities. It is argued that new communicative dynamics lead to new critical thinking about public and private spheres, as well as the shifting linkages between them, thanks to new media. Both these sections of the article draw on theories of globalization, highlighting how they have focused on spatial transformations as part of contemporary social dynamics.

\section{What is new about blogging in terms of blurring public and private spheres?}

It can be argued that in common with many Web 2.0 (social networking) phenomena, blogging has contributed to embedding ${ }^{1}$ individualization in the public sphere of new media. However, there are a number of qualifications that instantly help us to probe the specific nature of such individualization. First let's say a little about the new challenges presented to our thinking about public sphere by the Internet.

The public sphere has traditionally been a core concept in the study of mass media and communications in liberal societies. In broad terms it represents the free flow of public discussion and exchange of views that is seen, in particular, as fundamental to the legitimacy of democratic systems. It is a concept that locates an open media realm as integral to the legitimating processes of liberal societies, including in terms of accountable structures of governance. Thus the concept of public sphere (most notably theorized by Jürgen Habermas) tends to carry with it a heavy normative baggage related to the workings of democracy. Power is part of this picture and thus the differentiated influence of individuals and different (elite etc) groupings and organizations within it. Critiques of the public sphere concept focus among other things on the 'ideal' nature of it and the problem of exclusions or limitations affecting groups such as women (see, for example, the range of debates in Calhoun 1992. See also Harcourt 1999 and Beetham and Valenti 2007)

Discussion of the public sphere has inherently focused on the modern (democratic and territorially defined) state/society relationship (see Habermas 1992, 1996).

As a sphere between civil society and the state, in which critical public discussion of matters of general interest was institutionally guaranteed, the liberal public sphere took shape in the specific historical circumstances of a developing market economy. In its clash with the 
arcane and bureaucratic practices of the absolutist state, the emergent bourgeoisie gradually replaced a public sphere in which the ruler's power was merely represented before the people with a sphere in which state authority was publicly monitored through informed and critical discourse by the people. (McCarthy 1992, xi. Emphasis in the original)

In the pre-new media mass media age defined by print and broadcast outlets, a lot about the public sphere could be taken for granted. These media traditionally mapped, in the main, directly onto key social boundaries such as the national and the local, and as such, reflected the particular characteristics of such national and local contexts, including through different languages (see, for example, Anderson 1991, 37 46). Transnational media of national origin, notably the BBC World Service, always and intentionally reached well beyond their boundaries, but their national roots remained evident and a key aspect of what they were communicating. In other words part of the broadcast role is to reflect the key characteristics of the British public sphere and to report on the world and to the world in those terms. The multichannel, transnational broadcast era from the latter part of the $20^{\text {th }}$ century based on satellite and cable technologies has given growing numbers of people access to growing numbers of public and private channels. But it is fair to say that to a large extent these can still be viewed in traditional public sphere terms in that they reflect the national public spheres in which they originate, and thus in turn the different national political and broadcast cultures (for a range of related material, including from critical perspectives, see for example Mohammadi 1997).

These points make it clear that the concept of the public sphere, as it has been most familiar in the study of media and communications, has in effect mirrored how societies have been organized as polities, economies and cultures along national and local lines. Thus the public sphere has implicitly been a concept incorporating ideas about the spatial (territorial) organization of societies into distinctive and clearly segregated (bounded) entities. The publics of public spheres are by their very definition different from one another to large or small extent in relation to: languages, cultures, political systems, types of economy, histories, public and private broadcasting traditions, levels and types of governmental (political) control or regulation, etc (Anderson 1991, 37-46; Dahlgren 2001). 
Public sphere traditions are most closely associated with highly developed democracies, notably in the US and Europe, where patterns of free speech, lack of centralized political control over media, and the role of public and private media in facilitating free flow of information from top to bottom and vice versa, are among defining qualities. The Internet and the World Wide Web are respectively American and European inventions, and as mass media of a new kind, their operation reflects western free flow public sphere values. But the inherently anarchic and boundary crossing nature of new media necessitates expanded thinking about the public sphere, and the phenomenon of blogging is illustrative of why this is the case.

The public sphere of traditional mass media has context inherently contained in it. For example, the majority of people consuming such media (whether local or national) would traditionally have been located within, or associated with, the public sphere within which the media is generated. These audiences could be assumed to bring some kind of foundational historical knowledge of the specific context to the material they are accessing. And this is probably still the case for many consumers of such media. But now that this (traditional print and broadcast) media is online (via the web), it is also being presented out of its specific public sphere context, and open to access by increasing numbers of people who may be completely or only slightly knowledgeable about that context. This raises whole ranges of questions about contrasting forms of media literacy, which will doubtless become more prevalent in analyses of different aspects of new media consumption. When audiences are selfselecting and boundary crossing, including across national borders, something is happening to conventional understandings of the public sphere.

Theorizing about processes of globalization has included the notion of social relations being 'stretched' across time and space (see Giddens 1991) and it is interesting to think about public sphere contexts being stretched in similar ways. This may be a more accurate conceptual approach to public sphere discourses, including the individualized ones associated with blogging, than ideas about the possible development of a global public sphere or spheres (see also Sparks 2001). My reason for saying this is that all such discourses (whether formal and mediated or informal and individual) are generated out of specific public sphere settings, knowledge of which may be relevant to evaluation of the information and opinions being expressed. One of the many contributions of conceptualizations of the public sphere is the 
awareness of the social context for information, whether this information may be considered mediated or unmediated.

Blogging may be an entirely new form of online communication, but as with most things, it has its antecedents, and it is useful to think a little here about these with regard to the points just raised about context. We can regard the myriad forms of blogging (media, commercial, hobbyist, political, personal to name a few) as an anarchic cacophony of individual voices, some of which might be regarded as expert and many non-expert, and some attached to traditional public sphere organs such as newspapers and broadcasters, and many just personal blogs about daily life, interests, travel, etc. Individual voices, including as different forms of feedback or audience engagement, are not new in themselves in the public sphere, 'letters to the editor' in traditional print media, perhaps being the archetype, but radio phone-ins continuing to be a familiar form (and now text-ins and emailing-in).

This type of feedback still tends to fit into the one to many vertical traditional mass media form - in other words the mass broadcaster is initiating and constructing the 'opportunity' for audience involvement. It still has a top-down frame, in key respects, for example there will be a selection process of voices to be heard even if new media (text or email) are the means of contact. This is a good illustration of both how the old and new media worlds now increasingly overlap and how the use of new media (regarded as a horizontal many to many medium) is not always necessarily disrupting the (vertical one to many model) of old media. Citizen journalism type blogs or other kinds of activist or individual blogs are among those seen as most revolutionary partly at least because of their operation outside of the traditional media gate-keeping and editing processes. Their unofficial (unmediated) status is part of what many see as their fulfilment of the utopian promise of the free flow technology of the Internet.

The time and space qualities of blogging are interesting departures in this setting, because their nature as extended and often elaborating texts takes the question of 'voice' into whole new domains when we think about public sphere and context. The nature of the World Wide Web allows for text to be permanently and constantly accessible and open to archiving (see, for example, media academic and journalist Jeff Jarvis's site at http://www.buzzmachine.com). Although access to online material is influenced by myriad factors ranging from the access to basic information and communication technologies to get online at all, to the ordering rationales of search 
engines. As with other online material, blogs can serve as their own context, as it were, defined by where they are located, how they are constructed, and what kinds of information they contain. They may be semi-official, for example, by experts such as journalists, and located on their media outlet's website, but incorporating what may appear to be personal professional 'background' insights into particular news stories or reporting activities.

They may be in a similar vein but posted on a site which is individual to the journalist rather than part of the media outlet's official website (see, for example, the list at http://wiki.cyberjournalist.net/jblogs-independent). In the case of the first, the context (semi-official blogs) may be considered a mix of the official media website, the journalist's professional work, and his or her own personal insights on that work. In the case of the second, the context of the official media website is missing but if this journalist is a prominent writer for that organ then he or she indirectly carries some of its authority. ${ }^{2}$ We can think of other contrasting kinds of more personalized professional blogs such as those written by celebrities on their official sites.

Websites may offer a whole lot of supporting material that in its own right makes up some kind of official or authoritative quality to the voice. And again, as well as professional commentary, there may be insights of a more personal professional kind. With celebrities on their official sites, the context is very much focused on them as a brand, and the reader may wonder how much of the blog the personality actually has time to write him- or herself or how much of it might have to be put together on their behalf. The 'personal' connection with the fan is clearly a major part of celebrity culture so the voice of the blog might be interpreted as primarily or at least substantially located in that context. And just like any other kind of website blogs cannot just be taken at face value, as the highlighting of fake (parody) and public relations, marketing type ‘flogs' have indicated (see Times Online May 23 2008).

Political blogs, of members of parliament or of local councils, might be considered to have a context that is primarily official or public as they are defined by the job or role of the individual concerned and affairs connected with that, but this does not mean that both personal insights on that professional realm, or purely private facets, may not be woven into the blog, again perhaps in part to make that 'personal' connection with potential voters. The UK Tory leader David Cameron’s domestic scenes in his video blog took on iconic status along these lines ${ }^{3}$. Activist blogs might 
be considered along similar lines to political blogs in being centrally defined by the job or role and matters directly connected ${ }^{4}$.

Individual or personal blogs could seem on the face of it much simpler than the blogs referred to above, in the sense that they are usually predominantly private in sharing personal news, for example, with family and/or friends. However, the public can come into play in unexpected ways, if say a potential employer should refer to the blog and find information considered negative to the blogger's application. And recently the corporate development of policies covering employees and blogging and other social networking activities is attracting attention (see, for example, Cisco's Internet Postings Policy March 24 2008). This flags up the possibility that the public/private connections are not always foreseeable, and may surprise in totally unexpected and even very negative ways for the blogger. This point has been made with regard to personal data posted online, and how when it is gathered together, it can be very useful for the purposes of identity theft - obviously not what the posters were thinking about when posting.

We can see across these limited examples both some of the range of different forms of blogging and the different mixes of blurrings of public and private, institutional and personal. Indeed these examples would indicate that such blurring is fundamental to much of the activity and intentions (as well as sometimes unexpected consequences) of blogging. So, the phenomenon of blogging (like Web 2.0 social networking activities more generally) raises, as a prime consideration, public and private identifications and their connections and misconnections. It would follow that public/private linkages impact on the whole process of blogging: the reasons why one would blog; the nature and content of the blog; the kinds of readers it might be aimed at etc (see, for example, Pew Internet and American Life Project 2007).

Relating these points to public sphere considerations about new media adds further dimensions to our thinking. Back to the earlier point about contexts, what we might consider blogging to be is a form of individualized public sphere activity. For while blogging concerns individual voices, thanks to the nature of new media these are not just voices in a vacuum. As already indicated the location of the blog, its form and content, all contribute to how it may be regarded, and in addition to the points covered earlier, this goes well beyond distinctions between, for instance, fact and opinion. We might want to ask what kinds of facts, presented for what purpose, what kinds of opinion (professional, personal and so on) and for what purpose. Judgements 
about such areas are likely to contribute to the level and kind of authority, authenticity and trust granted to the blog by different audiences.

Individual blogs have individual audiences of wide-ranging scales so while not exactly comparable to traditional media, they can be considered to have a readership/audience that may be dedicated in similar ways to those who buy certain newspapers, listen to or watch certain programmes as a regular habit. Self-selecting interactive engagement is a characteristic of the new web world, which may be considered to be generating perhaps large numbers of mini-public spheres through specific blogs or groupings of blogs focused on similar issues or concerns. These are individualized both on the basis of production and consumption: that is through the individuals who are providing them and the individuals who are consuming and interacting with them. Assessing the 'status' of blogs is complex in terms of content, how much general prominence they gain and for how long, how many people are reading and interacting with them etc.

This is where the idea of embedded individualization is useful. I am thinking along the lines of the quantity as well as quality of blogs and engagements with them. This could be regarded as part of a process of individualization of supply and demand, where thanks to the ease of authoring and potential access to audiences that web technology facilitates, the menu open to individuals to communicate their own voices and to consume the voices and thoughts of other individuals has grown, and can be expected to continue to grow, exponentially. This could be argued to be embedding a new individualistic turn in the practice of, and attitudes to, public sphere engagement. Such interaction may be taking place across as much as within national (public sphere) boundaries, so it complicates our thinking about the public sphere in a number of ways. For instance, public spheres are being stretched beyond the traditional geospatial (territorially bounded) configuration via sociospatial (virtual space online) (see Youngs 2007). Depending on your perspective, such developments might be seen as contributing to a new ultra-pluralistic forms of public sphere or a challenge to more unified senses of public sphere (see Dahlgren 200, 39).

Blogs on mainstream media sites could certainly be regarded as an indication of a modified public sphere approach, integrating new forms of horizontal (individualized) engagement with more traditional (collective) forms. This is the case even if we take into account the market imperatives for traditional media to get on the new media 'interactive' bandwagon for audience and/or profit motives (see, for 
example, Wired July 14 2006). The hybrid character of established media in combining their traditional 'mass' (vertical) role with new (horizontal) forms, including blogging, is one of the most notable developments of the new media era. There is clear evidence here of traditional media using new media to expand its influence in new ways, and this is just as important, if not possibly more so, than the activities of the new individual bloggers.

\section{The new geopolitics of public spheres in the era of blogs}

This section focuses further on the spatial complexities of thinking about the blurring of public/private spheres in the era of blogs. The intention is to contribute to critical thinking about the implications of new media phenomena for understanding the virtual transformations in diverse public sphere (mini-public sphere) engagements. What is happening when blogs 'located' in specific public spheres can be accessed way beyond them in both geographical and public sphere regards. There needs to be a little discussion here of what is meant by location before proceeding with this point. As already touched on, public spheres are traditionally defined in terms of time and space, they extend over the history of a particular national (territorially-bounded) context. Their relevance has always extended beyond that context but in pre-Internet times mass access to the media of individual public spheres beyond their boundaries was virtually non-existent, and certainly 'out of reach' in contrast to the ease of access the online world now increasingly facilitates.

Here again current debates about public sphere in the new media age mirror to some extent debates that have already taken place in globalization studies, including the need to distinguish (as geographers most notably do) between (physical) place and (social) space. 'While communicative space becomes more independent of place, issues of the relationship between place and space remain very current. One normative requisite for the public sphere in this regard, over which there is not much controversy, is the congruence between geographical political entities and the public sphere as a communicative space’ (Dahlgren 2001: 38).

Inbuilt into the public sphere, as with all national stories, is the element of history, and the sense that there is generally likely to be some background knowledge through which new information entering the public sphere is interpreted. Such knowledge will have been gained over varying lengths of time and may have a very long history for citizens who have engaged regularly in the public sphere over their 
lifetime. So, as is often stressed in critical considerations of the meanings of political community, time is as important as space ${ }^{5}$. Public spheres are not only historically constructed, consequently featuring similarities and distinctions across them, but individuals' interactions with them also have their own histories, which may be diasporically as well as nationally located (see, for example, Georgiou 2006)

We can see clearly now that public spheres are being 'stretched ${ }^{6}$ by the Internet's enabling of access to them across as much as within national political boundaries. It is important not to assume the diverse meanings behind such stretching and it is not the intention to do that here. Whatever such developments indicate they are in their relative infancy, as is attention to, and critical thinking about, them. Just a few tentative points are worth making. The predominant containment of public spheres within geographical boundaries (as has typified most of their history in modernity) has been transcended in many ways by the communicative fluidity of the Internet and mass media and individual commentary within it, including through blogs. Major barriers, notably those of language, remain and those should not be underestimated. But it is also worth thinking more about the less obvious barriers to do with the nature of the public sphere and what participation within it signifies, actually or potentially, or should signify in a normative sense.

If an embedding of individualization in the public sphere through new media phenomena such as blogs, is occurring as suggested in the previous section, then it is important to look at this against the backdrop of traditional public sphere configurations in time and space. In the 'sociospatial ${ }^{77}$ context of the Internet, we are talking about multiple public spheres, which can be accessed at will and partially or in varying degrees on a kind of 'pick and mix' basis. To put it simply, people may be accessing blogs 'located' in different public spheres from outside of them as much as from within them. Knowledge relevant to public sphere activity has always varied enormously even for people within them, for example understanding of political systems and cultures, but in the Internet era, that variety has expanded dramatically. Individuals may be accessing information generated within a public sphere, who have vast amounts of knowledge about that sphere, but equally they may have virtually none at all. Perhaps this situation is also a strong reminder for us of the heterogeneity of public spheres per se, and the 'ideal' nature of the notion a homogeneous of public sphere. Before the new media era, scholarship on 'alternative media' in different contexts was among the work that addressed such considerations (see, for example, 
Downing 2003). Peter Dahlgren (2001: 39) points out: 'Democracy needs multiple and alternative public spheres . . . The ideal of a unified citizenry all engaged in talking in the same discursive mode in a singular space seems a bit stilted given today’s societal landscape.' And with the ‘stretching' of public spheres sociospatially in the online world, we may need to think in increasingly complex ways about the interactions of them.

There is not space here to explore in detail the full implications of this new situation, but it does highlight some key considerations for thinking about the nature of blogs, the relevance (or otherwise) of their 'locations', and qualitative issues related to the consumption of them. These points suggest that there is likely to be a revived interest in public sphere issues as new media activities such as blogs continue to grow in both number and impact. One of these issues is context in its broadest senses. For whether we are thinking about open democratic systems or closed repressive ones, the distinctive qualities of individual public spheres affect how things are articulated within them and what kinds of meanings can be read into them. The background knowledge that has facilitated understanding in such areas has been to some extent taken for granted in traditional public spheres. The sense is that these largely concern citizens who will have at least some, and in many cases, a great deal of awareness of such factors. These are in essence an intrinsic part of their lived experience as members of, and participants, in these spheres.

The self-selecting mini public spheres of the blogosphere, where individuals may be accessing a small or large number of blogs of different kinds from within one public sphere or across many, raises a whole host of new questions about the process of exchange that is happening. In terms of their consumption habits, we could picture blogging audiences as configured in highly differentiated ways. This picture is not instead of considerations of what we might think of as mainstream rather than alternative blogging, in other words the vertical concentrations of audiences as opposed to the horizontal more diverse ones that exist online as much as offline. The new media environment combines concentrations of networking activity, as social networking giants like Facebook graphically demonstrate, as well as more disparate (horizontal) patterns of activity (see also Gibson et al. 2003).

Audiences may be operating within a single public sphere which may be their own or another, or they may be surfing across a whole host of different public sphere contexts online to access myriad blogs, to some of which they might bring a great deal 
of knowledge about the context and to others of which they might bring almost none. It is worth remembering here that the 'locations' of blogs is not just about political spheres, it of course relates to specialist interests such as sport and culture. The context of these blogs will often be primarily the actual topic of interest. So the more general issues, discussed here in relation to political spheres, may in many cases be less important.

What is being emphasized here is the utility of thinking about blogging as a process, which is generated out of a context that may or may not affect in varying degrees its content and style, and equally how meanings are generated within it and communicated to and read by (and perhaps misread by) its diverse audiences. The Internet has (in online regards) disrupted the traditional mapping of the public sphere supply and demand sides. It is interesting to think about the extent to which most online information, including blogs, is generated out of specific public sphere contexts, but its consumption is a much more hybrid affair. It might be going too far to argue that this indicates a fairly high level of informational risk in the blogosphere for bloggers as much as their audiences. The blogosphere is variegated in this sense, because the audience/producer distinction may be eroded, for example where in a small community operating over an extended period those participating in reading and blogging may develop high levels of knowledge and trust. Other blogging environments may be far more heterogeneous and perhaps more problematic. It may be that expert blogging arenas carry less risk in certain circumstances where those reading and blogging on them have specific knowledge by which to judge the veracity and significance of the content. But the following question is pertinent. When audiences are so unpredictable and diverse in terms of their relevant background knowledge, how does one guarantee effective and clear communication?

So perhaps there are limits to the individualization and the sociospatial reach indicated in the previous section. Limits in practice rather than in theory. What this means is that the growing levels of social networking in Web 2.0 developments are demonstrating dramatically the art of the possible, the reach of communication, but also the constraints on the effectiveness of that reach. The growing potential for individual voices to reach out and communicate with others also brings into play the multiplicity of barriers, well beyond the obvious one of language, that exist to the effectiveness or meaningfulness of that communication. Indeed my own study of new media and its uses over the past decade leads me to assess that questions of 
meaningfulness in terms of much that happens online will increasingly move up public and individual agendas.

Raising this point is not meant to recall the old online/offline (virtual/real) binary argument that the former is always going to be inferior or problematic compared to the latter. Quite the contrary, the exponential growth of horizontal online activity in recent times has done much to affirm the pointlessness of such a hackneyed standpoint. What is of interest is the qualitative nature of what goes on offline and online, the contrasting ways in which online and offline activities and information interface, and the myriad meanings across them. Blogs are among growing varieties of online information being produced and consumed. They have relatively quickly become part of the public sphere, in the sense that the informational paths connected to them and their audiences weave in and out of offline as well as online realities (including those related to media).

'Geospatial' (territorial) and 'sociospatial' (virtual) realities ${ }^{8}$ are contributing to the form of public spheres and engagements within them in contemporary times and hybridity is the name of the game. Such developments follow the thematics of globalization, where the world is becoming increasingly interconnected and interdependent, and where social relations (private and public) are increasingly 'stretched'9 across distance. Globalization debates have long emphasized the problems of trust and risk ${ }^{10}$ in such circumstances, where our lives are increasingly mediated by expert systems, of which the hardware and software of ICTs are a prominent example. Web 2.0 phenomena such as blogging, if the points outlined above are accepted, illustrate continuities between analysis of new media and of globalization.

We do live in a new informational risk age where it is much harder to take context for granted, whether we are supplying or accessing information. The opportunities of the blogosphere are not without risks of miscommunication or partial communication, and in the hybrid sociospatial environment, these exist as prominently for those providing information as well as linking to it. It can be argued that this is an important dimension of the individualized nature of blogging, or more precisely the reflective practices that may need to be increasingly part of the phenomenon by those who blog and those who read blogs. And by all in policy, commercial and educational realms interested in different ways with new media 
literacy, and the potential of new media forms to generate political, economic, social and intellectual value.

\section{Conclusion}

In many ways bloggers are pointing towards the new future of new media, which is as horizontal as it is vertical, and where individualization is bound to have many new manifestations, unexpected as well as anticipated, and many new forms of reflexivity ${ }^{11}$ that will be required to make them work effectively and productively. This is a new informational risk age where individual voices may be much more plentiful and accessible, but often even more difficult to assess as trustworthy, reliable or relevant. To growing numbers of people across the world writing and/or reading blogs has already become as important, or interestingly even more important, an activity than the old fashioned reading of the daily newspaper. The validity of private voices, including but by no means always on public concerns, has moved up the new media agenda, for major commercial players including traditional media, as much as for individuals in their own right.

But this inevitably means that many of us will have to spend much more of our time assessing what those voices mean, what their contexts are and how that affects how we should think about their contributions. It is likely that growing attention will be given to the range of skills and knowledge needed to make judgements about online material. Media literacies of the past are being adapted to the new media age, and increased policy and educational focus can be expected in this area. The selfselected mini public spheres of the present and future, where individuals mix and match their online informational diet, from within one public sphere or across many, is very different from the historic territorially defined public spheres of the mass media era. But as stressed, the online/offline worlds overlap and intersect, including through blogging and its contexts and connections.

Individual media selections have always required reflexivity but the suggestion of the arguments presented here is that this will be even more the case in the future than in the past. The new media world of the blogosphere has demonstrably expanded individualization in terms of production and consumption, and contributed to blurring the public/private spheres in what may be revolutionary ways. If so, revolutionary forms of individual reflexivity are likely to be needed. 
Notes

1. The use of this term here is inspired by Anthony Giddens (1991) early work on globalization, where he discusses 'disembedding mechanisms'. 'These "lift out” social activity from localised contexts, reorganizing social relations across large time-space distances' (53). I am framing blogging as a connected phenomenon that is in turn embedding new forms of individualism within new media processes that in themselves are facilitating the kind of disembedding Giddens is referring to here. See also Tomlinson (1999).

2. The prominent environmentalist George Monbiot (monbiot.com) is interesting in this regard. His articles appear regularly in The Guardian newspaper and his own site includes an archive of those articles.

3. See webcameron at http://www.conservatives.com/tile.do?def=webcameron.index.page.

4. See, for example, Greenpeace weblogs site at http://weblog.greenpeace.org/makingwaves.

5. There has been interesting critical theoretical work in the field of international relations on this area. A key work remains Walker (1993).

6. See Giddens (1991: 64) discussion of this concept.

7. See Youngs (2007) for full discussion of this concept, which refers to the virtual setting of online social interaction.

8. See Youngs (2007).

9. See note 6 .

10. Giddens (1991:29-36) has discussed these areas extensively as part of the process of globalization. Ulrich Beck is the most well known commentator on risk in this regard. See, for example, Beck (1992, 1999).

11. See Giddens’ discussion (1991: 36-45) of reflexivity and modernity.

\section{References}

Anderson, Benedict. 1991. Imagined Communities. London: Verso.

Beck, Ulrich. 1992. Risk Society: Towards a New Modernity. London: Sage.

Beck, Ulrich. 1999. World Risk Society. Cambridge: Polity Press.

Beetham, Gwendolyn and Jessica Valenti, eds. 2007. Special Issue: Blogging 
Feminism Web(sites) of Resistance. The Scholar and Feminist Online.

http://www.barnard.edu/sfonline/blogs/aboutis.htm.

Calhoun, Craig (ed.). 1992. Habermas and the Public Sphere. Cambridge MA: MIT Press.

Cisco’s Internet Postings Policy, March 24 2008. Accessed June 192008 online at http://blogs.cisco.com/news/comments/ciscos_internet_postings_policy.

Dahlgren, Peter. 2001. The Public Sphere and the Net: Structure, Space, and Communication. In Bennett, W. Lance and Robert M. Entman (eds). 2001. Media Politics. Communication in the Future of Democracy. Cambridge: Cambridge University Press, 33-55.

Downing, John D. H. 2003. Audiences and Readers of Alternative Media: The Absent Lure of the Virtually Unknown. Media, Culture and Society 25(5): 625-645.

Georgiou, Myria. 2006. Diaspora, Identity and the Media. Cresskill, NJ: Hampton Press.

Gibson, Rachel, Paul Nixon and Stephen Ward (eds). 2003. Political Parties and the Internet. Net Gain? London: Routledge.

Giddens, Anthony. 1991. The Consequences of Modernity. Cambridge: Polity. Habermas, Jürgen. 1992. The Structural Transformation of the Public Sphere.

Cambridge: Polity Press. Originally published in German in 1962.

Habermas, Jürgen. 1996. Between Facts and Norms: Contributions to a Discourse Theory of Law and Democracy. Cambridge, MA: MIT Press.

Wendy Harcourt (ed.). Women@Internet. London: Zed.

McCarthy, Thomas. 1992. Introduction in Habermas, Jürgen. 1992. The Structural Transformation of the Public Sphere. Cambridge: Polity Press, xi-xiv.. Originally published in German in 1962.

Mohammadi, Ali (ed.). 1997. International Communication and Globalization. London: Sage.

Pew Internet and American Life Project. 2007. Report on Teens and Social Media 12.19.2007. Accessed June 192008 at http://www.pewinternet.org/reports.asp?page=2.

Sparks, Colin. 2001. The Internet and the Global Public Sphere. In Bennett, W. Lance and Robert M. Entman (eds). 2001. Media Politics. Communication in the Future of Democracy. Cambridge: Cambridge University Press, 75-95. 
Times Online May 23 2008. Consumer Protection Law Tackles Fictitious Blogs. Accessed June 192008 at http://timesonline.typepad.com/technology/2008/05/newconsumer-pr.html.

Tomlinson, John, 1999. Globalization and Culture. Cambridge: Polity.

Walker, R. B. J. 1993. Inside/Outside: International Relations as Political Theory. Cambridge: Cambridge University Press.

Wired July 14 2006. 'His Space’ accessed online June 192008 at http://www.wired.com/wired/archive/14.07/murdoch.html.

Youngs, G. 2007. Global Political Economy in the Information Age: Power and Inequality. London: Routledge.

Bio: Gillian Youngs PhD is a Senior Lecturer in the Department of Media and Communication, University of Leicester. She has been researching new media for a decade and has contributed to related policy processes in national and international contexts. Her publications include Global Political Economy in the Information Age: Power and Inequality (Routledge, 2007). 